International Journal of Current Advanced Research

ISSN: O: 2319-6475, ISSN: P: 2319 - 6505, Impact Factor: SJIF: 5.995

Available Online at www.journalijcar.org

Volume 6; Issue 4; April 2017; Page No. 3166-3168

DOI: http://dx.doi.org/10.24327/ijcar.2017.3168.0213

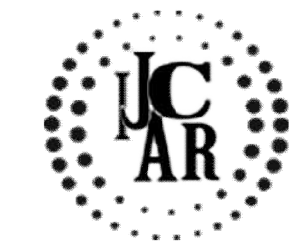

Research Article

\title{
DIFFICULTIES IN PERFORMING ROOT CANAL TREATMENT AMONG UNDERGRADUATES OF DENTAL COLLAGES IN SOUTH INDIA - A QUESTIONNAIRE BASED STUDY
}

\author{
Kayalvili Sanmugam
}

Saveetha Dental College, Saveetha University Chennai

\begin{tabular}{|c|c|}
\hline A $R$ R T I C L E I N F O & A B S T R A C T \\
\hline Article History: & Aim: The aim of this study is to investigate the difficulties and amount of time encountered \\
\hline $\begin{array}{l}\text { Received } 11^{\text {th }} \text { January, } 2017 \\
\text { Received in revised form } 19^{\text {th }} \text { February, } 2017 \\
\text { Accepted } 22^{\text {nd }} \text { March, } 2017 \\
\text { Published online } 28^{\text {th }} \text { April, } 2017\end{array}$ & $\begin{array}{l}\text { by undergraduate dental students during performing root canal treatment. } \\
\text { Objective: The objective of this study deals with the difficulty level of students in isolation } \\
\text { of the operating field, access cavity, locating root canal orifice, instrumentation of root } \\
\text { canal, obturation and also the time taken for access cavity preparation, canal preparation } \\
\text { and obturation. }\end{array}$ \\
\hline Key words: & $\begin{array}{l}\text { Methods: A questionnaire is distributed to } 200 \text { dental undergraduates in South India. } \\
\text { The levels of difficulties during performing access cavity preparation, instrumentation, }\end{array}$ \\
\hline $\begin{array}{l}\text { Difficulties, Root Canal Treatment, } \\
\text { Undergraduates }\end{array}$ & $\begin{array}{l}\text { isolation and obturation of the root canals and also information regarding the time spent on } \\
\text { procedures will be recorded based on categorised groups. } \\
\text { Background: A root canal is a treatment used to repair and save a tooth that is badly } \\
\text { decayed or becomesinfected. During a root canal procedure, the nerve and pulp are } \\
\text { removed and the inside of the tooth is cleaned and sealed. Without treatment, the tissue } \\
\text { surrounding the tooth will become infected and abscesses may form. Steps can be taken to } \\
\text { eliminate or reduce the difficulties of students in performing RCT. }\end{array}$ \\
\hline
\end{tabular}

Copyright $\mathrm{C} 2017$ Kayalvili Sanmugam. This is an open access article distributed under the Creative Commons Attribution License, which permits unrestricted use, distribution, and reproduction in any medium, provided the original work is properly cited.

\section{INTRODUCTION}

Endodontics is one of the fastest-growing disciplines in daily clinical practice ${ }^{(1)}$ which involves the introduction of many new instruments, materials and techniques. Root canal treatment is technically demanding and it fails when treatment falls short of acceptable standards. In an effort to provide patients with most recent and predictable treatment planning, clinicians must be well informed about the outcome of endodontic treatment. It is important to acknowledge that outcome of root canal treatment is dependent not only on specific factors like root canal infection, complexity of root canal morphology, but is also very much influenced by less specific, more distinct causes such as dentist's skills and attitudes. ${ }^{(2)}$ Dentistry is an extensive program that requires a lot of efforts, encouragement, and clinical exposure. The anatomical diversity of root canals, the need to provide adequate care to the patients and the lack of selfconfidence among students led many of them to consider endodontics to be difficult and stressful discipline, while performing the endodontic treatment. ${ }^{(3)}$ Information related to technical difficulties and time devoted to root canal treatment treatment may help emphasize points of weakness and lead to improving teaching and training methods. The present study aimed to identify the difficulties and amount of time

*Corresponding author: Kayalvili Sanmugam

Saveetha Dental College, Saveetha University Chennai encountered by undergraduate dental students in performing root canal treatment based on their perceptions and to remove these shortcomings by laying more emphasis on these areas, at the same time, create better skills among students to perform quality endodontic procedures.

\section{MATERIALS AND METHODS}

A questionnaire survey dealing with the difficulties and the amount of time encountered by undergraduates in performing root canal treatment is conducted among dental colleges in South India. A structured questionnaire with 17 questions was distributed to 200 dental students from various dental collages. The questionnaire contained information regarding the amount of weekly working hours in the endodontic department. Information regarding the level of difficulty experienced by the student during creating access cavity, maintaining an aseptic field, locating the canal orifice and obturating the root canal was recorded in a categorised manner from a scale of $(0-4)(0$ defined as very easy, 1-easy, 2-moderate, 3-difficult and 4-very difficult). Additional information considering the amount of time spent on access cavity preparation, mechanical root canal preparation and obturation of the root canal were also recorded.

\section{RESULT}

In this study, students do not feel any difficulties in performing root canal treatment in the anteriors.52.5\% of students feels difficult in making access cavity in 
Table 1

\begin{tabular}{|c|l|c|c|c|c|}
\hline Scale & \multicolumn{2}{|c|}{ Access cavity } & Aseptic operating field & Locating canal orifice & Instrumentation of root canal \\
\hline & In anteriors & In posteriors & & & \\
\hline 0 & $11 \%$ & $0 \%$ & $23 \%$ & $11.50 \%$ & $9.50 \%$ \\
\hline 1 & $75 \%$ & $5 \%$ & $45 \%$ & $15 \%$ & $27.50 \%$ \\
\hline 2 & $14 \%$ & $25 \%$ & $25 \%$ & $62.50 \%$ & $48 \%$ \\
\hline 3 & $0 \%$ & $52.5 \%$ & $7.50 \%$ & $11 \%$ & $12.50 \%$ \\
\hline 4 & $0 \%$ & $17.5 \%$ & $0 \%$ & $0 \%$ & $2.50 \%$ \\
\hline
\end{tabular}

Table 2 Time devoted by undergraduate students for endodontic treatment

\begin{tabular}{cccc}
\hline Time & $\begin{array}{c}\text { Time taken for access } \\
\text { cavity preparation }\end{array}$ & $\begin{array}{c}\text { Time taken for } \\
\text { canal preparation }\end{array}$ & $\begin{array}{c}\text { Time taken for } \\
\text { canal obturation }\end{array}$ \\
\hline $0-15 \mathrm{~min}$ & $38 \%$ & $6 \%$ & $0 \%$ \\
$16-30 \mathrm{~min}$ & $45.50 \%$ & $42 \%$ & $49 \%$ \\
$31-45 \mathrm{~min}$ & $12.50 \%$ & $30 \%$ & $32 \%$ \\
Above 45 minutes & $4 \%$ & $22 \%$ & $19 \%$ \\
\hline
\end{tabular}

posteriors. $45 \%$ of them feels it's easy to make an aseptic operating field. $48 \%$ of students gave a moderate scale for the instrumentation of root canal.Coming to the time devoted by the students for endodontic treatment, $83.5 \%$ of them spend half an hour or less than that for making an access cavity. $22 \%$ of then takes more than 45 minutes for canal preparation. $49 \%$ of the undergraduate spend half an hour for the obturation of the canal whereas $19 \%$ of them spend more than 45 minutes for canal obturation.

In this study, students do not feel any difficulties in performing root canal treatment in the anteriors. $52.5 \%$ of students feels difficult in making access cavity in posteriors. $45 \%$ of them feels it's easy to make an aseptic operating field. $48 \%$ of students gave a moderate scale for the instrumentation of root canal. Coming to the time devoted by the students for endodontic treatment, $83.5 \%$ of them spend half an hour or less than that for making an access cavity. $22 \%$ of then takes more than 45 minutes for canal preparation. $49 \%$ of the undergraduate spend half an hour for the obturation of the canal whereas $19 \%$ of them spend more than 45 minutes for canal obturation.

\section{DISCUSSION}

In recent years, endodontics has been one of the fastest growing areas of dentistry. The use of modern tools, rubber dam and the microscope in daily practice, significantly influence the quality and durability of treatment effects. Patients more often do not identify the endodontic treatment as the most unpleasant procedure. Pain associated with endodontic procedures, although still arousing the strongest emotions, is felt as moderate, rarely sharp. A study conducted by Klages et al. demonstrates that patients visiting the dental office expect pain usually larger than that actually experiencing during treatment. ${ }^{(4)}$

Undergraduate endodontic teaching has an important role in the practice of endodontic by general practitioner. One reason for the relatively poor technical standard of root canal treatment among the general practitioner may be the limited endodontic teaching received at dental schools. ${ }^{(5,6)}$ difficulties at undergraduate might faces during their endodontic practice. Abier Ali Ibrahim et $a l^{(7)}$ stated in their study that maintaining an aseptic field was the most difficult procedure among vast majority of students. Similarlythis survey shows that undergraduates do not practice single-visit root canal treatment and majority of them uses rubber dam for isolation. The use of the rubber dam during root canal treatment offers three main advantages: control of crossinfection, protection and improving treatment efficiency. ${ }^{(8)}$ Due to these benefits, proper infection control by isolating the operating field with a well-fitting rubber dam has been strongly recommended by professional organisations. (European Society of Endodontology 1992, 2006, American Association of Endodontists 2004).

In this study, regarding the percentage of difficulties encountered by the students during access cavity, $72.5 \%$ of them having difficulty in reaching the pulp chamber. $43 \%$ of students having difficulty to feel the apical constriction during working length determination.Similarly, [Mubashir Baig Mirza $]^{(9)}$ in his study stated that the maximum level of difficulty faced by the students was to detect the apical constriction during working length determination.In this study, $85 \%$ of them never experienced strip perforation before and $22 \%$ of them having difficulty in flaring up the canal during cleaning and shaping. In a study conducted by [Mubashir Baig Mirza] ${ }^{(9)} 43.5 \%$ of the students also frequently experiencing difficulty in flaring up of the canal.Whereas, for the percentage of difficulties encountered by students during obturation, $40 \%$ of them have experienced master cone beyond apex during obturation.

Recent literature validate that root canal treatment at the present is mostly carried out in molar teeth. ${ }^{(8)}$ However, a molar tooth is probablya much technically challenging tooth to due to its complex anatomy, hence expectedly higher technical quality of root canal fillings were recorded for single rooted teeth in opposition to multi rooted teeth. ${ }^{(10)}$ Similarly, in this study undergraduates feels it's difficult to perform access cavity in posteriors. Time for completing root canal treatment is an important factor that might hypothetically influence the treatment outcome. Instrumentation of the root canal and obturation the root canal 
was the most time demanding procedure, rather than time needed to open the access cavity. ${ }^{(11)}$ In this study, there is noticeable obstacles among undergraduate students where $52.5 \%$ of the them rated a scale of 3 (difficult) in making access cavity in posteriors. Also obturating the root canal appeared to be the most time demanding procedure.

\section{CONCLUSION}

In conclusion, the survey helped to find out about difficulties faced by the students in endodontic treatment. Undergraduate students are spending more time for the obturation of the root canal and having a difficulty in flaring up duringinstrumentation of the canal. Students should be encouraged and guided properly to overcome these errors and perform a better treatment.Further research with larger number of sample need to be done to get even more accurate results.

\section{References}

1. Chan AWK, Low D, Cheung GSP, Ng RPY: A questionnaire survey of endodontic practice profile among dentists in Hong Kong. Hong Kong Dental Journal, 2006;3(2):80-87.

2. Ruchi Gupta1, RochnaRai, The Adoption of New Endodontic Technology by Indian Dental Practitioners: A Questionnaire Survey, Journal of Clinical and Diagnostic Research. 2013 Nov, Vol-7(11): 2610-2614

3. Rolland S, Hobson R, Hanwell S. Clinical competency exercises: Some student perceptions. Eur J Dent Educ 2007;11(3):184-91.
4. Magdalena JanczarekmariaCieszko-Buk, Teresa Banchanek, RenataChalas, Survey based research on patient's knowledge about endodontic treatment. PolJ Public health 2014;124(3):134-137

5. Barrieshi-Nusair KM, Al-Omari MA, Al-Hiyasat AS. Radiographic technical quality of root canal treatment performed by dental students at the dental teaching center in Jordan. J Dent. 2004; 32:301e307.

6. Qualtrough AJ, Whitworth JM, Dummer PM. Preclinical endodontology: an international comparison. Int Endod J. 1999; 32: 406e414.

7. Abier Ali Ibrahim, NehalBasheerFadlalla, NorelhudaFathalrahmanNory, Neamat Hassan Abubakr,Difficulties in performing root canal treatment among dental students in Sudan, Indian Journal of Dentistry 2012 OctobereDecember Volume 3, Number 4; pp. 196e 200

8. Ahmad I. Rubber dam usage for endodontic treatment: a review. Int Endod J. 2009; 42:963e972.

9. Mubashir Baig Mirza,Difficulties Encountered during Transition from Preclinical to Clinical Endodontics among Salman bin Abdul Aziz University Dental Students: Journal of International Oral Health 2015; $\mathrm{S}(1): 22-27$

10. Bjørndal L, Laustsen M, Reit C. Root canal treatment in Denmark is most often carried out in carious vital molar teeth and retreatments are rare. Int Endod J. 2006; 39:785e790.

11. Balto H, Al Khalifah S, Al Mugairin S, Al Deeb M, AlMadi E. Technical quality of root fillings performed by undergraduate students in Saudi Arabia. Int Endod $J$. 2010; 43:210e300.

\section{How to cite this article:}

Kayalvili Sanmugam (2017) ' Difficulties In Performing Root Canal Treatment Among Undergraduates Of Dental Collages In South India - A Questionnaire Based Study', International Journal of Current Advanced Research, 06(04), pp. 3166-3168. DOI: http://dx.doi.org/10.24327/ijcar.2017.3168.0213 